\title{
Iridium's impact
}

David Payne relates iridium's role in two very different ages.

T he story of iridium is both modern and prehistoric. It was discovered along with osmium in 1803 by the British chemist Smithson Tennant, born in 1761 in Selby, Yorkshire. Tennant studied medicine but after graduating found it unsuitable for his temperament, and focused on chemistry instead. In 1785, despite not having yet published any scientific papers, he was elected a Fellow of the Royal Society at the young age of 23 . Although he published few papers during his career, they were of great significance - he demonstrated for example that diamond consisted solely of carbon ${ }^{1}$.

Tennant discovered elements 76 and 77 , osmium and iridium respectively, by collecting insoluble black impurities derived from the treatment of platinum ore with aqua regia. He treated them with caustic soda before carrying out an extraction step with hydrochloric acid, which was repeated a number of times. From this he obtained red crystals, most probably $\mathrm{Na}_{2}\left[\mathrm{IrCl}_{6}\right] \cdot n \mathrm{H}_{2} \mathrm{O}$, that when heated gave a white powder, which Tennant stated was "not capable of being melted, by any degree of heat I could apply"2. He named the element iridium after Iris, messenger of the gods in Greek mythology and the personification of the rainbow, owing to, in his own words, the "striking variety of colours it gives" when the metal is dissolved in hydrochloric acid ${ }^{2,3}$.

\section{Insulating states of iridium}

\section{oxides are predicted to display exotic physics.}

The physical properties of iridium were apparent from the moment of its discovery with a very high melting point $\left(2,447^{\circ} \mathrm{C}\right)$, hardness (1,760 MPa) and density $\left(22.56 \mathrm{~g} \mathrm{~cm}^{-3}\right)$ - over twice that of lead and only just beaten by osmium. It is one of the least abundant elements in the Earth's crust - about forty times less abundant

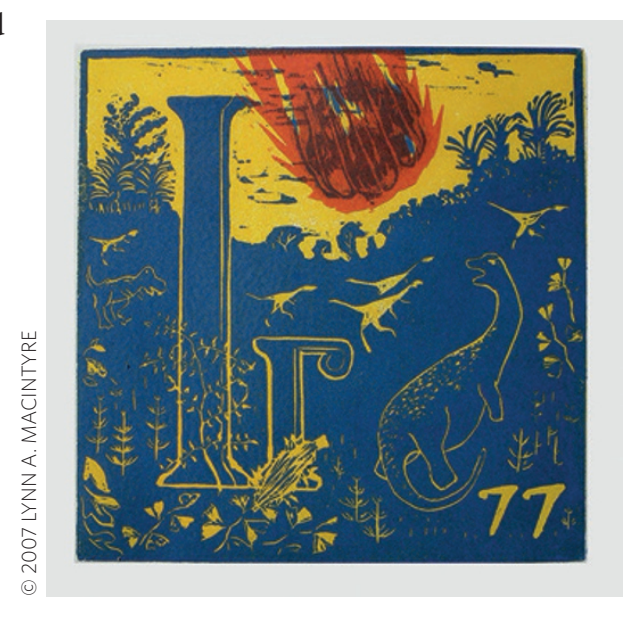

than gold. It is thought to have sunk to the Earth's core during the formation of the planet, owing to its siderophilic (ironloving) nature. Only three tonnes are produced annually, mainly as a by-product of the electrorefining process of copper and nickel, therefore making iridium an expensive commodity.

Despite its rarity, iridium has found uses in technology - albeit limited ones. Its high resistance to corrosion, including under high temperatures, makes it a desirable constituent in spark plugs and engine parts, for example, in aviation applications. Iridium is also commonly found in homogenous catalysis, with organoiridium compounds finding use in the carbonylation of methanol to acetic acid. Vaska's complex, $\operatorname{IrCl}(\mathrm{CO})\left[\mathrm{P}\left(\mathrm{C}_{6} \mathrm{H}_{5}\right)_{3}\right]_{2}$, used in oxidative addition reactions, has the unusual property of being able to reversibly bind diatomic oxygen.

The oxides of iridium have also attracted great interest in the last $10-15$ years. As a heavy transition metal with partially filled $5 d$ orbitals, the oxides would be expected to display metallic conductivity, yet relativistic effects (spin-orbit coupling to be precise) on the electronic structure, drive a number of the oxides into an insulating state. It is these insulators that have been predicted to display exotic magnetic and electronic physics ${ }^{4}$.

Recently element 77 had also made the news ${ }^{5}$ in chemistry through the isolated compound $\left[\mathrm{IrO}_{4}\right]^{+}$, which features iridium in the highest oxidation state observed so far, +9 . This makes iridium the element that displays the widest range of oxidation states (from -3 to +9 ).

Its modern developments are counterbalanced by the (literal) impact of iridium in the much older history of our planet: one of the great global catastrophic events. Sixty five million years ago, the Cretaceous-Paleogene (K-Pg) extinction event occurred, and marked the loss of $70 \%$ of the plant and animal species on Earth including all non-avian dinosaurs. The geological record is marked by the $\mathrm{K}-\mathrm{Pg}$ boundary, a thin layer of sediment, which was found to contain very high levels of iridium - much higher than the natural abundance in the Earth's crust. Asteroids are notably rich in iridium, and Luis Alvarez and colleagues ${ }^{6}$ postulated that the K-Pg extinction was caused by an asteroid impact; subsequently a suitably sized crater was discovered in the Yucatán Peninsula, Mexico. The theory that the extinction of the dinosaurs was caused by an iridium-rich asteroid strike is further backed up by the fact that no dinosaur fossils are ever found above the $\mathrm{K}-\mathrm{Pg}$ boundary. A significant amount of iridium present in the Earth's crust today came from this asteroid strike.

Element 77, which participated in the end of one age, finds applications and still holds surprises in the modern age.

DAVID PAYNE is in the Department of Materials, Imperial College London, Exhibition Road, London SW7 2AZ, UK. e-mail: d.payne@imperial.ac.uk

\footnotetext{
References

1. Tennant, S. Phil. Trans. 87, 123-127 (1797).

2. Tennant, S. Phil. Trans. 94, 411-418 (1804).

3. Griffiths, W. P. Platinum Metal Rev. 48, 182-189 (2004).

4. Zhao, L. et al. Nature Phys. 12, 32-36 (2016).

5. Wang, G. et al. Nature 514, 475-477 (2014).

6. Alvarez, L. W. et al. Science 208, 1095-1108 (1980).
} 